\title{
LENGUAJE Y PODER EN LA POESÍA DE MARÍA SALGADO Y DE ÁNGELA SEGOVIA
}

Language and power in the poetry of María Salgado and Ángela Segovia

\author{
Guillermo Molina Morales \\ Instituto Caro y Cuervo (COLOMbia) Guillermo.Molina.Morales198@gmail.com
}

RECIBIDO: 23 DE ENERO DE 2018

ACEPTADO: 6 DE MAYO DE 2018

RESUMEN: En el presente artículo, estudiamos tres propuestas actuales que trabajan con la materialidad del lenguaje para generar disidencias en la dimensión política de la poesía. En ready (2012), de María Salgado (1984), se expone una búsqueda de la errancia a través de la pérdida, del desclasamiento, para lo que se rompe con el discurso gramatical cerrado. Hacía un ruido. Frases para un film politico (2016), de la misma autora, experimenta un desborde democrático a través de la técnica del "collage", que permite operar con un gran cantidad de materiales heterogéneos recogidos en el ámbito público, sobre todo en torno al movimiento 15-M. La curva se volvió barricada (2016), de Ángela Segovia (1987), nos implica en una lucha contra el "dominio" (entendido como todo poder cerrado) que amenaza a un sujeto definido desde su cuerpo de mujer. En conjunto, los tres libros suponen una relevante propuesta de apertura en el panorama poético español.

PALABRAS ClAVE: María Salgado, Ángela Segovia, poesía española contemporánea, poesía y poder

ABSTRACT: In this paper, we study three present proposals working with language to create political dissent through poetry. ready (2012), by María Salgado (1984), suggests an experience of loss towards being classless. Hacia un ruido. Frases para un film politico (2016), by the same poet, try a democratic overflow through a "collage" of heterogeneous verbal materials collected in the streets. La curva se volvió barricada (2016), by Ángela Segovia (1987), displays a struggle against every closed form of power that threatens a subject defined by her woman corporality. Overall, these three books mean an outstanding attempt to expand the limits of Spanish contemporary poetry.

KEYWORDS: María Salgado, Ángela Segovia, Spanish contemporary poetry, poetry and power

Molina Morales, Guillermo

"Lenguaje y poder en la poesía de María Salgado y de Ángela Segovia"

Kamchatka. Revista de análisis cultural 11 (Julio 2018): 221-238

DOI: 10.7203/KAM.11.11407 ISSN: 2340-1869

Monográfico LECTURAS DEL DESIERTO: NUEVAS PROPUESTAS POÉTICAS EN ESPAÑA 
En el presente artículo, estudiaremos tres propuestas poéticas que coinciden en el intento de cuestionar el ámbito sociopolítico de nuestro tiempo a partir de un trabajo desestabilizador con el lenguaje. Se propone que ambos aspectos, la intervención social y la experimentación formal, están necesariamente unidos, y que este hecho fundamenta la potencia expresiva de los libros estudiados. Su importancia en el panorama poético español se incrementa al considerar las dinámicas más visibilizadas de las últimas décadas, que intentaremos perfilar en esta introducción. Para ello, nos serviremos de críticos valiosos que denuncian, desde diversos ángulos, el conservadurismo estético que ha caracterizado a la poesía española reciente.

El primero que citaremos, Agustín Fernández Mallo, propone una interesante comparación entre la evolución de la poesía española (al menos, de lo que él llama "poesía ortodoxa") y la experimentada en otras artes, como la pintura y la música, a partir del momento de comunión que supusieron las vanguardias históricas. En un tono cercano al manifiesto vanguardista, el poeta gallego reclama "la necesidad de que los poetas acometan sin complejos la deconstrucción de la poesía, única disciplina artística que aún no lo ha hecho" (2009: 25). Interesa subrayar que, según Fernández Mallo, una de las causas de este desfase es la peculiaridad del material con que trabajan los poetas: las palabras, a diferencia de los colores o las notas musicales, se relacionan de forma inmediata con los referentes externos, lo que ha generado cierta servidumbre del significante hacia el significado.

En un sentido similar, pero desde un enfoque más decididamente sociológico a la hora de señalar las causas, Vicente Luis Mora denuncia la imposición de una "poesía de la normalidad" que acierta a definir de esta manera: "[El poema] ha de cerrarse en sí mismo, presentar una clara estructura, tener una factura simbolista, terminar con un corolario de tipo moral, describir ambientes urbanos con referencias utópicas (...), situarse en entornos sociales burgueses de clase media/alta y estar armado siempre en estructura cerrada, inatacable" (2006: 49). En la práctica, este dictum dificulta la experimentación con la materialidad textual del lenguaje y relega a un segundo plano a los poetas que intentan superar esta barrera implícita.

Uno de los críticos que mejor ha reflexionado sobre esta problemática es Antonio Méndez Rubio, que continúa el trabajo teórico del Colectivo Alicia Bajo Cero. En sus textos, señala una existencia permanente de conflicto en el ámbito sociopolítico, que las diversas instancias de poder intentan acallar. Según Méndez Rubio, el mundo "trabaja para que el conflicto no le dañe, para que no lo altere como mundo existente", lo que, en la práctica poética, se traduce en el fomento de lo que Mora llamaba "poesía de la normalidad". Sin embargo, el crítico extremeño enfatiza que "el daño para la poesía no es una opción: es una necesidad" (2004: 121). En consecuencia, todo poeta comprometido con su oficio y con la sociedad debería escribir desde el conflicto, y no desde su evitación a partir de poemas cuya ortodoxia lingüística refuerza los imaginarios del poder. Unos imaginarios que se fundamentan, precisamente, en la supuesta transparencia y neutralidad del lenguaje.

Los tres teóricos que acabamos de citar, nacidos en los años sesenta, se refieren en varias ocasiones a la polémica en torno a la "poesía de la experiencia", que para ellos suponía, en los años ochenta y noventa, el mayor ejemplo de ortodoxia dominante. Si bien es cierto que las derivaciones de esta poética todavía son muy visibilizadas (piénsese, por ejemplo, en la 
"poesía ante la incertidumbre"), en la segunda década del siglo XXI podemos constatar la persistencia de las dinámicas anteriores sin necesidad de referirnos a ningún grupo concreto. La mayoría de los poetas nacidos en los años ochenta y recogidos en antologías recientes como, por ejemplo, Nacer en otro tiempo (2016) y Re-generación (2016), muestran un tipo de escritura que no se diferencia mucho de la definición que daba Mora para la "poesía de la normalidad". El último premio Loewe, concedido a un poeta nacido en 1984, Ben Clark, por La policía celeste (2018), puede ser entendido como otro hito en la canonización de un relevo generacional sin riesgos estéticos.

Con todo, en esta misma década de los ochenta nació un buen número de poetas que da muestras de entender el poema como un espacio de conflicto. En este sentido, Alberto Santamaría señala en este grupo la puesta en escena de un sujeto poético "esquizofrénico, politizado también en muchos momentos, irremediablemente desprendido de sí, dividido. En unos casos esta división recae en una fractura interna (o psicológica) y en otros en una fractura entre el yo que habla y el lenguaje" (2017: 75). En este segundo conjunto de propuestas, en las que es "el lenguaje el elemento desde el cual trazar radicalmente el problema de la escritura poética" (76), podemos ubicar la obra de María Salgado y de Ángela Segovia.

En la línea de teorizaciones como la citada de Méndez Rubio, las poetas que estudiaremos coinciden en pensar que una poesía que no experimenta, que no permite al lector superar lo previsto, es, por definición, conservadora. La poesía no cambia el mundo de forma inminente (ni siquiera una revolución cambia algo más que la superficie), pero sí puede generar espacios para imaginar de forma distinta el mundo en que vivimos (y toda lucha política es, de forma prioritaria, una lucha desde/hacia los imaginarios simbólicos). De aquí nace la concepción de la poesía como un trabajo profundo con las formas de expresión/ indagación, en busca de inestabilidad crítica. Es decir, el lenguaje en estado de revuelta permanente contra sí mismo para situarse de forma honesta frente al tiempo en que vivimos.

El objetivo principal de este artículo, además de visibilizar propuestas valiosas que no se encuentran en las antologías al uso, es analizar cómo dialogan lenguaje y poder en las obras de María Salgado y de Ángela Segovia. Es decir, qué estrategias lingüísticas utilizan las autoras para ampliar la percepción de las relaciones sociales y, de esta manera, abrir espacios de ruptura en el ámbito público. Para definir la palabra "poder" nos basamos en los propios libros analizados, en los que esta palabra (la palabra "dominio" en el caso de Segovia) se relaciona con todo orden discursivo cerrado que recluye al sujeto en los límites de un único imaginario para interpretar el mundo.

En concreto, nos centraremos en tres libros recientes: ready (2012) y Hacia un ruido. Frases para un film politico (2016), de Salgado; y La curva se volvió barricada (2016), de Segovia. El hecho de centrarnos en libros ya publicados, y no en las trayectorias de sus autoras, pretende ser coherente con el énfasis otorgado a la materialidad del lenguaje, además de evitar el peligro de valorar propuestas que todavía están en pleno desarrollo. 


\section{READYO LA BÚSQUEDA DE LA ERRANCIA}

María Salgado (Madrid, 1984) ha publicado, hasta la fecha, cuatro libros de poesía: ferias (2007), 31 poemas (2010), ready (2012) y Hacía un ruido. Frases para un film político (2016). Aunque el gesto experimental es visible desde sus primeras obras, se percibe una radicalización en los dos últimos libros. Se trata de una evolución plenamente consciente que se acompaña con numerosas reflexiones, tanto en contexto académico (la autora se doctoró con una tesis sobre poesía experimental española) como en proyectos auto-gestionados de aprendizaje colectivo (en especial, el Seminario Euraca). Además, la poeta explicita su propuesta en poéticas publicadas como tales o como partes integrantes de sus creaciones, en donde encontramos una decidida apuesta por el trabajo con el lenguaje: "lo que construye la poesía es una distorsión de los discursos, también políticos; por eso propicia saltos de comprensión, pero no ofrece programas de puntos ni argumentarios" (en De la Torre, 2016: 232). Como vemos, aquí el compromiso no se confunde con la emisión de mensajes unidireccionales.

En esta concepción de la poesía, Salgado, al igual que Segovia, se apoya en algunas experiencias radicales provenientes de América, tanto del Sur como del Norte. En especial, Salgado, que vivió en Buenos Aires una fructífera temporada, se vincula directamente con poetas argentinos que ensanchan de diversas maneras los límites de lo poético como una forma de desafiar al modelo neoliberal imperante: Martín Gambarotta, Sergio Raimondi, Wáshington Cucurto, Fernanda Laguna, Daniel Durand, Alejandro Rubio, Martín Rodríguez, etc. Por el lado norteamericano, es muy relevante la importancia del grupo $\mathrm{L}=\mathrm{A}=\mathrm{N}=\mathrm{G}=\mathrm{U}=\mathrm{A}=\mathrm{G}=\mathrm{E}$, que en España fue reivindicada en los años noventa por Pujals Gesalí, aunque no encontró mucho eco en aquel entonces. Ambos grupos, el de los poetas argentinos (que a veces se agrupan, de manera imprecisa, en rótulos como "poesía argentina de los noventa" o "tendencia materialista") y el de los poetas norteamericanos, han sido ampliamente trabajados en el Seminario Euraca, en el que participan nuestras dos poetas.

Concretamente, ready está constituido por cinco secuencias de fragmentos de escritura, entendidas como campos de fuerzas no lineales. Ninguna de las páginas puede asimilarse a un poema cerrado o independiente. En todas las series se busca la experimentación formal, aunque esta es más notable entre las páginas 77 y 91, que incluyen experimentaciones tipográficas, citas intervenidas y un amplio listado de ciudades, igualmente intervenido. En conjunto, ready supone un libro hacia la errancia, hacia una errancia que, en un primer momento, se construye a partir de la negatividad, contra el imaginario y los recursos asentados por la tradición. En consecuencia, los antagonistas principales son el lenguaje de la identidad y la identidad del lenguaje. Es decir, la fuerza del lenguaje (sobre todo, del lenguaje escrito) para encerrarnos en definiciones, y las definiciones cerradas sobre el lenguaje, que se basan, entre otros aspectos, en la utilización de frases con "sentido completo" y la consecución de poemas "redondos".

Pero ready es, sobre todo, una experiencia en búsqueda de la errancia, proceso inacabado que se despliega a lo largo de la obra. Hay una palabra clave en este sentido: "desclasarse". En el libro, es constante el esfuerzo por salir de los moldes prefijados, lo que conlleva una lucha 
difícil, e incluso dolorosa. Tomaremos como punto de partida para nuestro análisis un fragmento que gira en torno a este concepto:

la clase desgasta a sus hijos en affaires con los iguales desclasarse desgasta mucho más, se trata de affaires más frágiles (2012: 41).

Estos versos se pueden entender de dos maneras, necesariamente complementarias. Por un lado, como una cuestión de clase social, como un intento de escapar a las limitaciones de un estrato acomodado para interactuar con las realidades de otros grupos sociales ("no habitabas como yo en un pequeño bourg ajardinado / ennoblecido al pequeño boom desarrollista gracias", 2012: 35). Por otro lado, los versos pueden leerse como una declaración metapoética: la autora opta por salirse de los códigos habituales para lograr una experiencia a la intemperie.

La apuesta hacia la errancia (hacia la extranjería, podríamos decir en un sentido amplio) está marcada por el desgaste y la fragilidad. Escapar de lo conocido genera la necesidad de crear unas relaciones diferentes (con el lenguaje, con la sociedad), que se caracterizan por la indefinición, por la ausencia de referentes sólidos. Este hecho puede ser, en ocasiones, frustrante ("ready se desclasa y cómo duele"), pero supone una enriquecedora práctica de la pérdida, decididamente asumida desde las primeras páginas: "pero no lo voy a comprar, lo voy a perder" (2012: 19). La oposición entre la pérdida (el desgaste, la fragilidad) y el sistema de acumulación capitalista ("comprar") nos recuerda que estamos ante una decisión política, que radicaliza todavía más la dedicación a algo tan improductivo como es la poesía. Desde otro punto de vista, esta marginalidad genera un espacio de mayores posibilidades de ruptura: "la poesía es barata".

La opción de la autora en su libro puede relacionarse, como lo recuerda Trotter, con la desterritorialización descrita por Deleuze y Guattari, ya que "al desclasarse, ready traza líneas de fuga por donde escapa de la máquina capitalista, y busca las grietas, los resquicios o los intersticios de vida que quedan allí donde la vida misma ha sido proletarizada" (2013: 228 29). Sin embargo, quizás resulte más interesante situar la propuesta de Salgado en el debate sobre la literatura de izquierda, un debate retomado en Argentina por Damián Tabarovsky (2004) durante los años de formación de la autora en el país suramericano. La propuesta básica del ensayista es asociar la disidencia con la "pura negatividad", es decir, con el rechazo absoluto a cualquier forma de conexión con lo social, ya que esta siempre podría ser pervertida por el mercado, la academia, etc. En Salgado, como lo vimos anteriormente, existe un primer movimiento de negación, el "desclasarse" que le permite salir de lo previsto: escapar, por ejemplo, tanto del sentimentalismo individualista como de la sintaxis clásica (sujeto + verbo + objeto). Sin embargo, ready no busca el aislamiento hacia una "comunidad inoperante" (otro asunto es que esta comunidad sea improductiva desde la perspectiva del capitalismo), sino una operación de conexiones abiertas y dinámicas, siempre dubitativas: “¿harías el amor en un corte de luz?” (2012: 60).

Una buena forma de comprobarlo es a través de los sujetos, de las subjetividades, presentes en la obra. En primer lugar, de nuevo, existe una negación, que podemos concretar, 
con Tabarovsky, como una lucha contra "el principio de identidad cartesiano del individuo como identidad autoconsciente unificadora" (2004: 26). Ahora bien, en el libro sí existen sujetos, ya desde el título, ready, que es el nombre del "protagonista" (y que remite tanto al "ready-made" de Duchamp como al "ready to lose" de una cita de Matta-Clark). También encontramos a la "xinesa" y al "xinés" (nótese cómo el uso de los términos catalanes produce extrañamiento, en lugar de situar a los personajes en la geografía de Barcelona, en la que no se insiste). E incluso podemos imaginar la subjetividad de la autora implícita del libro (no necesariamente María Salgado), ya que se muestra en el acto de escribir y, sobre todo, de dudar acerca de la escritura. Y, a su lado, ciertas compañías fantasmales, desde la aparición momentánea de voces que se nombran ("soy samuel beckett") hasta los autores de las citas que la autora reelabora.

Con todo, la peculiaridad de los nombres mencionados empieza a darnos pistas sobre su forma de existencia. O son nombres reconocibles que se diluyen en un texto colectivo (por ejemplo, "roberto bolaño", que aparece extensamente citado e intervenido) o son nombres comunes ("xinesa", "ready") que pueden ser temporalmente ocupados por cualquiera: se trata del "yo, por ejemplo" que aparecerá en el libro siguiente. En todo caso, ninguno de estos "personajes" tiene una identidad definida, sino que aparecen como nodos frágiles de un sistema de relaciones sociales explorado por un lenguaje igualmente frágil, o ya directamente roto ("hace que pulsa pul / sos de un mensaje que no es su // yo", 2012: 32). En este sentido, el libro rehúsa la trampa del individualismo, al tiempo que inserta las subjetividades en un entramado dialógico: "mi extensión de lo que no / me pertenece un nombre / en medio". Este hecho, por cierto, nos invita a descartar la tentación de leer el libro como la secuenciación de la vida de un/a tal ready, aunque existan al principio escenas de nacimiento, y escenas de muerte al final del libro (pistas falsas que, quizás, sean contraproducentes para los objetivos de la obra).

El libro, insistimos, está escrito desde una materialidad concreta, la del lenguaje y la del cuerpo ("hay una guerra abierta en cada cuerpo y nadie / domestica esta impaciencia", 2012: 67), pero la autora evita conscientemente que esa materialidad se cierre en una identidad fija. Desde esta perspectiva, nos parece importante analizar cómo ready indaga en el tema del amor, tan ligado tradicionalmente al sentimentalismo individualista. Partamos de la estrofa que abre la serie "Xino / empieza el libro":

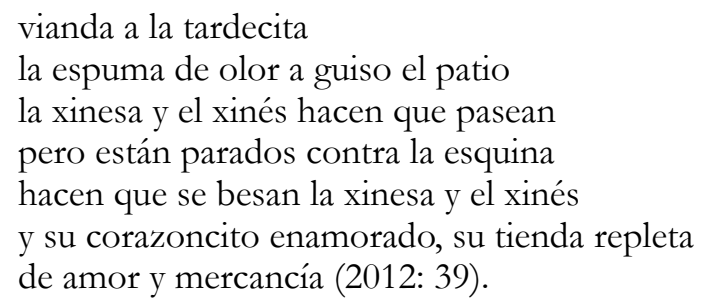

Hay aquí una historia de amor, una simulación de una historia de amor con olor a guiso, y mercancías: los tres elementos al mismo tiempo y con el mismo nivel de importancia. Es decir: existen sentimientos fuertes en los sujetos ("su corazoncito enamorado"), pero estos sentimientos son modelados según los patrones culturales ("hacen que se besan", como se besan en las películas) y toman su forma definitiva dependiendo de circunstancias concretas 
(no es igual el amor en una "tienda repleta de (...) mercancía" que en una llena de deudas). Sin duda, uno de los mayores logros de la autora es la complejidad con la que conviven la ternura, la ironía y la visibilización de las circunstancias sociales, que suelen localizarse en espacios periféricos de las ciudades, lugares de convivencia de distintos grupos sociales, como los locutorios. En este sentido, resultan menos logrados los fragmentos de lectura unívoca (que, por suerte, son muy esporádicos), como la sátira en "la epilepsia que al final deslucía / las reuniones familiares" (2012: 13).

La última serie del conjunto, "bajo el arc del triomf", es igualmente interesante por la relación que se establece entre el amor y la lucha política, una relación que se explicita con referencia a la novela Doctor Zhivago. En concreto, el sujeto poético se cuestiona su sentimentalidad: "horas lamentables de trabajo mercenario en países sin estado / y sólo pensamos en nuestro privado y vergonzoso amor" (2012: 100). El amor y la ideología, desde luego, no son incompatibles, sino que deben dialogar para un enriquecimiento mutuo. La tentación primera es, simplemente, oponerlos (el amor como refugio y energía contra un mundo injusto), lo que resulta de gran efectividad emotiva, como se comprueba en los poemas de Miguel Hernández y de Jorge Riechmann. Algo de esto hay en la serie, que a veces se revela demasiado sentimental, pero importan sobre todo los fragmentos en que se produce un verdadero diálogo entre amor e ideología, un cuestionamiento de los principios:

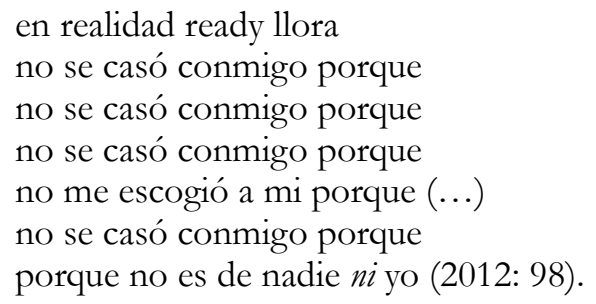

Es posible una lectura en la que ready lucha internamente para superar las convenciones tradicionales ("lo que quiero perder se me resiste dentro", se dice en otro momento), que atan a las personas como si fueran posesiones privadas (son evidentes las connotaciones negativas que tiene el matrimonio en este contexto). Sin embargo, "en realidad ready llora". De nuevo, hay ternura (una necesidad insatisfecha), ironía (hacia esa necesidad y/o hacia la ingenua intención de superarla) y circunstancias concretas (la coherencia hacia unos principios que, por otro lado, siempre se consideraron frágiles). La épica de los fragmentos finales, especialmente de la última página, suscita de nuevo la pregunta sobre la necesidad de certezas.

Esta suerte de contradicción, o más bien de diálogo buscado, entre lo frágil y lo fuerte puede servir para introducirnos en los fragmentos que muestran de forma explícita los límites del lenguaje (es decir, una fragilidad máxima). Pensemos en los siguientes versos, referidos a un "deseo opaco de comunicación" asociado con la poesía:

es la angostura del deseo de cualquiera, es decir es no decir, es el paisaje inventado por la falta (de decir) (de no decir) (2012: 31).

Aquí experimentamos la imposibilidad de encontrar las palabras, o los silencios, para nombrar el deseo, para comunicarnos de manera completa. Por lo tanto, será necesario 
reinventar "el paisaje" a cada momento, con un decir complejizado, lo cual es liberador y doloroso al mismo tiempo, por lo que se requiere la fortaleza del "ready" que atraviesa el libro. La renuencia a utilizar un lenguaje programado supone la apertura de un espacio para la disidencia (nótese la diferencia respecto a los políticos o tertulianos que se vanaglorian de "hablar claro").

Recordemos que el lenguaje es una preocupación constante de todo poeta, no solamente por ser su única herramienta, sino también porque moldea las relaciones sociales. Es necesario, por lo tanto, forzar el lenguaje para encontrar perspectivas diferentes desde las que entender el mundo que nos rodea. Ahora bien, existen algunas propuestas en ready, cercanas a la tradición de la llamada "poesía visual", que quizás solo funcionen como recordatorios de la importancia del lenguaje. Nos referimos a páginas como "ready tiende su ropa sentimental", en la que vemos colgados elementos tipográficos que constituyen la materialidad del libro, o como el listado de ciudades al que ya nos hemos referido. La propia Salgado, en una poética escrita poco después de ready, y que forma parte de Hacía un ruido, reconoce su inclinación hacia la exploración extrema del lenguaje, y se muestra consciente del riesgo: "secar la imaginación e interiorizar la lengua hasta ensimismarla demasiado" (2016: serie 8). Por suerte, esto solo ocurre en contadas ocasiones.

En todo caso, no deberíamos olvidar que la decisión de la autora, su decidida apuesta por "perder", es valiente porque conlleva un peligro real: que el trabajo de escritura, los varios años de trabajo, no logren concretarse en una propuesta valiosa para el lector (para el artista, una experiencia de este tipo siempre va a ser enriquecedora, aunque solo fuera como aprendizaje). Imaginemos al escultor que se negara a producir una obra tradicional y que, de tanto desgastar la piedra, de tanto explorar su fragilidad, terminara ofreciendo una materia apenas perceptible para el espectador. ready se sitúa, e incluso traspasa en ocasiones, en el límite de la significación (la insignificancia suena atractiva como propuesta en este contexto, pero la puede producir cualquier algoritmo). Sin embargo, la autora sí logra crear una experiencia de lectura significativa para el lector, una experiencia que nos implica en la lucha por la errancia y que, sobre todo, la evidencia como una manera de superar los límites tradicionalmente impuestos a nuestra percepción, a nuestra vivencia, de las relaciones sociales.

\section{HACÍA UN RUIDO EN EL DESBORDE DEMOCRÁTICO}

Si ready suponía una experiencia del despojamiento, del desclasamiento, del ir perdiendo, el siguiente libro de María Salgado, Hacía un ruido. Frases para un film político parece situarse en el extremo contrario. Existe una voluntad común de superar los límites de la poesía como discurso sentimental individualista, pero en este caso se practica una suerte de poética del exceso. Es decir, en este libro se suman las voces de manera un tanto caótica, como un collage del ruido de las calles entre los años 2011 y 2015, especialmente del movimiento 15-M de España. Tomando como base eslóganes, entrevistas personales, discursos políticos, artículos de periódico, conversaciones cotidianas, etc., pero también experiencias en primera persona y reflexiones metapoéticas, se construye una "masa" textual que solo se modula a través de 
series y de disposiciones tipográficas (además del trabajo previo de selección, montaje y reelaboración de la autora, por supuesto).

Este procedimiento compositivo es relativamente novedoso. De hecho, Pujals Gesalí lo califica como radicalmente nuevo en la anquilosada poesía española (2017: 193). En cambio, sí podemos encontrar ejemplos en el cine, por ejemplo la película Mercado de futuros (2011), de Mercedes Álvarez. También en la poesía latinoamericana. Parece interesante mencionar el precedente de Roque Dalton en Taberna, poema que escribió en un tiempo de gran agitación política (entre los años 1966 y 1967) y que el propio Dalton presenta como "el recogimiento directo de las conversaciones escuchadas al azar", a las que el autor "dio el mínimo trato formal para constituir una especie de poema-objeto basado a su vez en una especie de encuesta sociológica furtiva" (1969: 76). El resultado es una suma de sentencias y opiniones políticas, preocupaciones cotidianas y peticiones de cerveza, sin excluir frases descontextualizadas y contradictorias. Claro que el caso de Salgado es más radical todavía, puesto que no se limita al formato tradicional de la sucesión de versos, e incorpora materiales más heterogéneos. Con respecto a propuestas contemporáneas, como el "apropiacionismo" de Goldsmith, que se basa en el simple ensamblaje de bloques de texto sin intervención alguna, Salgado trabaja de forma consciente para medir las continuidades y los choques de sentido. Es decir, hay un trabajo de reelaboración y montaje mucho más complejo.

Antes de seguir adelante, es necesario notar que el libro analizado es solamente una parte del proyecto total titulado Hacía un ruido. En efecto, Salgado, junto al músico Fran MM Cabeza de Vaca, realizaron una investigación compleja que dio lugar a diversos resultados, desde recitales hasta piezas audiotextuales. Si bien cada uno de estos frutos puede entenderse por separado, posiblemente sería más enriquecedor un análisis que los integre, objetivo que queda fuera de nuestras capacidades en este momento (resulta significativo, por cierto, que la poeta Segovia también investigue en formatos alternativos). Si tomamos la pieza impresa de forma aislada, algunos fragmentos pueden resultar incomprensibles, e incluso un tanto inadecuados, como la lista de vídeos que formaron parte de algunos eventos en vivo, y que se incluye en la serie 16, "Del ruido. Leyenda" (es decir: puede ser enriquecedor mostrar las "costuras" en el tejido al que pertenecen, pero no las costuras de otros tejidos).

La tesis central de Hacía un ruido (título que se refiere a la memoria del pasado reciente, pero también "hacia" el futuro, con las connotaciones activas del verbo "hacer") podría sintetizarse de la siguiente manera: las personas generamos una cantidad casi infinita de enunciados que, por su propia multiplicidad y divergencia, suele calificarse como "ruido" (y, por lo tanto, no ser escuchado), pero en ese ruido, en ese magma caótico, existen posibilidades significativas más vigorosas que en un discurso cerrado, sobre todo en los epicentros de momentos convulsos como la Puerta del Sol de Madrid alrededor del 15-M. La poética que articula el libro se resume brillantemente en una sección de la serie 4, "Una idea de la dificultad_aprox.":

como si significante no equivale a discurso sino a mundo como si significación no equivale a identidad sino a contradicción como si significativo equivale a precario a compromiso (2016: serie 4). 
Es decir, las palabras no organizadas de forma secuencial, sino moviéndose en libertad por la diversidad del "mundo" (el mundo de la doble página, en el libro) para generar choques de sentidos precarios, frágiles.

Esta idea se realiza plenamente en series como la segunda, "El problema de la democracia_aprox.". Se presentan aquí algunas experiencias personales ("entonces llama Marta para que corra hacia Cibeles"), eslóganes ("un mundo solo se para con otro mundo"), reflexiones ("todo esto es muy ingenuo, es una experiencia infrapolítica, es poética") y otros tipos de materiales. Estos enunciados, que utilizan distintos recursos tipográficos, se disponen como si la doble página fuera un lienzo, es decir, no existe una dirección, una secuencia de lectura tradicional (de izquierda a derecha y de arriba abajo). La tentación de otorgar centralidad a los eslóganes, que aparecen en negrita y tamaño de letra grande, se evita con su posición espacial periférica y con la existencia de flechas que los asocian a sus emisores concretos, lo que se reduce la posibilidad de generalizarlos. En consecuencia, la única "conclusión" que puede extraer el lector es que "el problema de la democracia" (y su oportunidad, añadimos) es su naturaleza "selvática", es decir, naturalmente desorganizada. Y la certeza de que "siempre hay un significante vacío", que en la doble página está representado por un rectángulo en blanco

Una serie muy distinta, pero igualmente lograda, es la que comienza con la frase "pero no se puede llegar alli’", a la que siguen ocho páginas que parecen reproducir una entrevista a campesinos de Galicia, a la manera de la escritora Luz Pichel. Este punto de partida podría llevar a un discurso plano o, lo que es peor, a explotar la carga dramática, emocional, de un grupo social vulnerable, como hacen los programas de televisión. El acierto de Salgado, sin embargo, es lograr que las palabras aparezcan llenas de dudas, de grietas, de palpitaciones, lo que deja espacio para la apertura de significados, hasta el punto de que no hay un "mensaje" propiamente dicho.

El procedimiento contrario al que busca Salgado es la imposición de explicaciones tranquilizadoras, lo que se cuestiona en varias series del libro. Por ejemplo, en la 5, "un mundo_aprox.", se ironiza contra la "trama" que resuelve "el enredo": "vence al cáncer porque es buena, vence al enemigo porque es buena, vence a la chica envidiosa que no es popular porque además de guapa es buena" (2016: 5). La última frase de la cita evidencia que estos modelos se difunden, sobre todo, en los medios de comunicación. En este caso, podemos adivinar la referencia a las películas comerciales, pero también es evidente el protagonismo de los noticieros en la difusión de ideas como la de "esta crisis tiene un principio y tendrá un final”. El problema es que la realidad no es fácilmente explicable, pero sí es muy susceptible de ser manipulada a través de simplificaciones que favorecen a la clase dominante.

Con todo, quizás sea discutible el uso de la ironía en algunos momentos del libro. En la mezcla de voces que propone Hacia un ruido, debe caber una amplia diversidad de perspectivas contrarias para que exista un verdadero diálogo y un cuestionamiento mutuo. El problema es la inclusión por extenso de enunciados tan elementales que no soportan un mínimo trabajo deconstructivo. Por ejemplo, en la página que comienza "ya / no hay / mujeres // como las de antes": los materiales tomados (artículos de Arturo Pérez Reverte, Javier Marías y Manuel 
Vicent) muestran tan rápidamente su estupidez, su vacío unívoco, que no es necesario insistir para lograr un efecto grotesco. Algo similar ocurre en el comienzo de la serie 14, "Un mundo aprox.": el discurso del empresario agresivo no está suficientemente matizado y, por lo tanto, se queda en la simple parodia (auto-parodia en este caso). Podría resultar más enriquecedor explotar las contradicciones. Por ejemplo, en el Museo del Alzamiento de Varsovia, siguiendo la idea de la "banalidad del mal" de Hannah Arendt, se muestran idílicas fotografías de personas que realmente parecían amar a sus hijos. Solo en los pequeños letreros al pie de foto el visitante descubría que se trataba de los máximos responsables de los campos de concentración.

Hay una serie del libro, la número 11 (titulada "Una historia de España. Sale quien habla"), en la que muy acertadamente se oponen estos dos tipos de secuencias enunciativas: la unívoca que se autodestruye y la dialógica. Aparentemente, ambas hablan en primera persona sobre la generación nacida en torno al año 1985, explicada desde sus antecesores, en la que surge la inconformidad y el deseo de cambio. El lector puede comenzar a empatizar con el primer discurso, pero pronto se introduce la sospecha: existe una coherencia excesiva y un deseo de cambio demasiado contenido dentro de lo aceptable por la sociedad ("tampoco traen una revolución política, sino un ideal de limpieza y de moralidad pública”). Esta sospecha se confirma al final del texto, en el que contemplamos el deslizamiento definitivo hacia una inocua propuesta de recambio político que incluso utiliza un lenguaje publicitario: "Bienvenido al nuevo horizonte, que sin duda puede abrirse mañana" (es curioso encontrar en Internet que en realidad esta frase, como otras del texto, procede de una columna de Manuel Vicent en "El País").

En cambio, el texto de la derecha es mucho más complejo. En primer lugar, porque incorpora un mayor número de perspectivas: por ejemplo, las de inmigrantes de Marruecos y Rumanía. En segundo lugar, porque el texto está permeado por la aparente oralidad, no reducida al filtro de la interpretación, por lo que las frases pueden parecer confusas o insignificantes. En tercer lugar, y sobre todo, este texto no tiene una dirección clara, sino que se mueve en espiral ofreciendo más dudas que respuestas. De hecho, la última frase es: "Amar, escribir significarse, no tener miedo, ¿̇son un poder etnográfico, de género, de clase o de lenguaje?". Como en ready, Salgado evidencia lo enriquecedor de movernos en el terreno de la fragilidad.

En la serie 9, "Un sujeto muy difícil. Quien sale habla" (nótese el énfasis en localizar los sujetos de enunciación), este posicionamiento político queda enmarcado en un contexto asambleario en el que parecen discutirse dos proyectos de disidencia (que, en realidad, no hay que entender como opuestos). El proyecto de desborde, que es el defendido por Hacía un ruido, contrasta con la idea de canalizar la inconformidad:

antes de que la lengua cambie o, hay quien dirá, crezca

antes justo de que se empiece a hablar de "hegemonía" y "mayoría" y "confluencia" y de ganar y de poder en primera persona del plural del imperativo

sería bueno capturar el umbral de aparición de algo que antes apenas sí (2016: 9) 
El lector español reconocerá fácilmente algunas palabras clave del discurso de Podemos (incluso el propio nombre en primera persona del plural), partido político surgido a partir del 15-M y que representa en este texto la opción de la disidencia canalizada. Sin embargo, también un lector extranjero que no conociera nada de la política española reciente podría sentir la distancia entre el ruido plural y el intento de formar una "confluencia" más homogénea. Lo mismo sucedería, por citar otro ejemplo, con el lector que no conociera el caso de Rodrigo Rato pero que sintiera la potencia de la pregunta que le dirigió un político de izquierdas, David Fernández: “¿Tiene usted miedo? (...) / A perderlo todo un día... A la gente / A que un día la gente se harte / ¿Usted tiene miedo?” (2016: 14). En estos casos, las circunstancias concretas, sin dejar de serlo, pueden experimentarse desde otras coordenadas espaciotemporales: un acierto del libro.

Ahora bien, la apuesta por localizar los enunciados (en el libro abundan las fechas, por ejemplo), de registrar la actualidad inmediata, parece discutible en otros momentos. Por ejemplo, la serie 12, "Mejor leer entre líneas: el voto naranja es un voto con subtexto de clase", puede resultar insignificante, desde el título, para casi todas las personas que no estén inmersas en la actualidad española de la segunda década del siglo XXI. Si no se conoce el contexto de la emergencia del partido neoliberal Ciudadanos (el "voto naranja"), de los movimientos independentistas catalanes, etc., el texto no generará ningún impacto en el lector. Por ejemplo, no se entenderá la ironía de una tal "Arrimadas", líder en Cataluña de Ciudadanos, hablando de derechos sociales. En cambio, cuando más adelante, en la misma serie, se dice "En California del Norte en 2012 algunos negros pobres votaron en contra del matrimonio gay", no es realmente necesario conocer las circunstancias concretas para generar una reflexión sobre la separación entre las luchas de distintas minorías sociales.

En definitiva, la propuesta política de Hacía un ruido es mostrar un desborde democrático (es decir, de múltiples voces no jerarquizadas) que no puede, que no debe, ser "interpretado" de manera unívoca, a posteriori, porque entonces su potencial se vería neutralizado. Pujals Gesalí (2017) se basa en esta idea para hablar de una poesía que se escribe en directo y que alcanza las resonancias de un poema épico, en cuanto que funciona como memoria colectiva de su tiempo. En realidad, la épica, basada en una voz sin fisuras que narra las hazañas de un héroe idealizado, podría más bien situarse en las antípodas de este proyecto, a no ser que nos refiriéramos a lo que Bertolt Brecht entiende por "teatro épico", que sería más cercano a la propuesta de Salgado. Por otro lado, el crítico catalán, en su desmedido entusiasmo por el libro, parece confundir los efectos generados por un poema con su proceso de construcción (por suerte, mucho más meditado y mediatizado de lo que aparenta).

Nuestra lectura se aproxima más a la de Baigorria, quien habla de "una vuelta más radicalizada hacia el materialismo de los noventa [en Argentina]" (2017: 65). En este contexto, entendemos el "materialismo" como un compromiso con la materialidad de los enunciados (es decir, con el lenguaje) y, de forma consecuente, como un rechazo a la abstracción, al "ascenso" hacia un mundo de ideas depuradas. Esta línea de trabajo, muy frecuentada en Latinoamérica, como nos recuerda Guerrero (2016), está resultando fértil en una buena parte de la poesía española reciente que busca nuevos caminos para situarse ante la realidad de nuestro siglo. 
En el contexto peninsular, Martínez Fernández se refiere a la "escritura del shock" para definir un grupo de propuestas que responden al shock político derivado de la crisis de 2008 a través de un shock estético de filiación vanguardista que mantiene un potencial liberador. En concreto, según Martínez, "la disolución del sujeto en múltiples voces permite no solo la incorporación de otros discursos y códigos en el poema, sino también la incorporación del lector al plano poético. La poesía, entendida en tanto estructura polifónica, abre un espacio de interrogación al lector" (2014: 412). Esto es, precisamente, lo que sucede en Hacia un ruido, en donde se interpela al lector mediante su inserción en una multiplicidad de voces sin dirección prefijada.

En todo caso, la nueva apuesta de Salgado, siempre en el límite, se sitúa al borde de un precipicio real. Así como ready tenía el riesgo de caer en la insignificancia por exceso de fragilidad en sus formulaciones lingüísticas, Hacía un ruido se enfrenta al peligro de lograr un verdadero ruido. El ruido, no lo olvidemos, se puede experimentar fielmente, durante horas y horas, en un autobús público, por ejemplo, sin que esa experiencia sea enriquecedora en su conjunto. El trabajo del artista es buscar las frases que puedan revelar una nueva percepción de la sociedad, por sí solas o, en la mayoría de los casos, en diálogo con otras frases. De esta manera, se posibilita que la experiencia del ruido (de la simulación del ruido, en realidad) sea significativa: "precaria", sí, pero también "comprometida", es decir, abierta a múltiples posibilidades de situarnos ante la sociedad. Por suerte, el balance de Hacía el ruido es francamente positivo: todo un viaje a la complejidad del presente.

\section{LA CURVA SE VOLVIÓ BARRICADA CONTRA EL DOMINIO}

El nombre de Ángela Segovia (1987) ha empezado a sonar en los círculos poéticos a partir de la obtención del Premio Nacional de Poesía Joven Miguel Hernández 2017, concedido por el Ministerio de Cultura español. Su obra, sin embargo, ya contaba con cierta resonancia entre los poetas y lectores más inconformistas, que valoraron positivamente sus tres primeros libros: ¿Te duele? (2007), de paso a la ya tan (2013) y el premiado La curva se volvió barricada (2016). En estas obras existe una coherencia en la exploración de los meandros del lenguaje: de hecho, el título del último libro proviene de un verso del anterior. Como en el caso de Salgado, la búsqueda poética se acompaña de reflexiones sobre poesía contemporánea, tanto en el área académica como en el debate entre pares (en el Seminario Euraca, por ejemplo).

Así pues, no extraña que la poesía de Ángela Segovia se mueva en coordenadas similares a las de María Salgado. Encontramos varios puntos en común: la influencia de la poesía latinoamericana de las últimas décadas (y de César Vallejo), con mayor énfasis en la chilena por parte de Segovia; el trabajo en la dimensión política del lenguaje a través del compromiso con su materialidad; la búsqueda de un "decir" inestable y frágil; la importancia concedida al componente visual y sonoro (incluso escénico) de la escritura; la atención prestada a los conflictos sociales del presente; etc. En este sentido, los fragmentos metapoéticos que Segovia incluye dentro de su libro guardan un cierto aire de familia con las ya comentados de Salgado. Pongamos un ejemplo: 
A la lengua como un flujo de ritmos sin sentidos, se opone la luz de la claraboya, como un ovni sin voluntad. el tipo de silogismo que le gusta practicar es el que tiene una herida. La herida del silogismo es tan grande que acaba por sustituirlo. La herida se llama: cansancio de significar (2016: 38).

Cansancio (y desconfianza) del lenguaje tradicional, trabajo de construcción desde la "herida" del orden discursivo, desde las renuncia a las simplificaciones unívocas que sostienen (y crean) un mundo injusto. Un programa de creación muy ambicioso y, como a continuación veremos, consecuente en sus prácticas.

La curva se volvió barricada es un poemario complejo que se organiza en torno a series heterogéneas. En algunos casos, como "(europxs)", la serie puede ser entendida como un conjunto de poemas. En otros, como "la funesta de allh", no sería posible establecer subdivisiones entre las páginas o los fragmentos que la conforman. Hay, en todo caso, un notable trabajo formal que incluye imágenes, gráficos y un constante juego con las tipografías, ya desde el formato del libro, que es horizontal. Estos rasgos invitan a practicar una lectura abierta que supere las limitaciones de la acostumbrada linealidad vertical. Es decir, el lector se mueve de forma relativamente libre a través de los múltiples caminos sugeridos.

El primer poema del libro funciona como una declaración de intenciones. Se habla de "millones de agujeros", de "una grieta" y, sobre todo, de una propuesta: "la verdad no hará dominio". Dominio de qué, podríamos preguntar. Dominio, simplemente. Es decir, se trata del rechazo a tomar posesión de cualquier tipo de certeza. Bueno Vera (2017), tras consultar la palabra "dominio" en el Diccionario de la Real Academia de la Lengua, así lo explicita: "habremos de entender también que la verdad no hará poder, territorio, orden o derecho. Y si lo hiciera, ¿no sería esto una forma de violencia?” (2017: 196). Se trata, por lo tanto, de un posicionamiento político a la vez que estético.

Puesto que este punto de partida es similar en los tres libros estudiados, puede resultar interesante conocer cómo se desarrolla de forma diferenciada en cada uno de ellos. Las dos obras anteriores, lo hemos visto, se generaban a partir de una idea que podríamos calificar, hasta cierto punto, de formal: el viaje hacia la errancia, hacia la pérdida (incluso pérdida de materia), en ready; y el "collage" en el que se multiplican las voces: Hacía un ruido. En La curva se volvió barricada hay una mayor diversidad. Junto a experiencias de desmaterialización y trabajo con la oralidad, hay series claramente narrativas ("aventuras de Nanet y Bone", por ejemplo) y poemas que pueden leerse como una unidad completa, por poner dos ejemplos. Lo que da unidad al libro no es tanto la inclusión de mapas que relacionan las distintas secciones, sino la presencia, en casi toda la obra, de un "yo" (y de otros personajes, en algunas series) que nos implica en su lucha contra distintas formas de "dominio".

Veamos cómo funciona esta estrategia discursiva, para lo que nos referimos a la ya citada serie "(europxs)", que comienza con unos versos de García Lorca: "por el arco del encuentro / la cicuta está creciendo". Tanto el título como el epígrafe orientan la lectura hacia una reflexión sobre las problemáticas del viejo continente en la era del "encuentro", de la globalización. Este trayecto, iniciado en una discoteca de Barcelona, será experimentado por un "yo" que se concreta, sobre todo, desde su cuerpo de mujer. El momento de mayor tensión se vive en el poema "toMé", cuyo primer verso, demasiado explícito ("bajé al pozo parco 
patriarcal"), nos señala una suerte de descenso a los infiernos. Pronto sentimos, a un ritmo frenético, una confusión de lenguas y de manos que, tras su aparente diversidad, comparten un mismo objetivo:

ellos son la europa multilingüe te sodomizarán sin un gemido no sentirán nada después escupirán palabras dirán feuer nutte dirán puta a lo callado dirán je parle jo parlo y i'm talking yo you cara de carne con la cara más dura que europa lo dirán un joven se acercó, nos ofreció un chicle de frutas, parecía preocupado yo me reí con sorna no estoy ahí, el m da sed, no? me fui será será (2016: 30).

Quizás lo más interesante del fragmento elegido sea el "no estoy ahî" del último verso: así es como la protagonista escapa de los sistemas de dominio de los hombres (que muestran en el poema sus dos vertientes, la agresiva y la paternalista). Pero, si no está ahí, ¿dónde está ella? ¿A dónde "fui será"? Posiblemente, a algún lugar de los intersticios del lenguaje, a un mundo posible que queda latiendo sobre los gritos de estos hombres simiescos: "supón que vale la pena / las trenzas se les llenan de sol / lo guardan para las lluvias" (2016: 32). La misma conclusión es posible en una lectura que interprete la serie con la clave de la política europea (podríamos imaginar lo sucedido con Grecia en los últimos años): hay todo un paisaje que inventar por encima de la prima de riesgo.

En este sentido, cabe la posibilidad de relacionar algunas estrategias de Ángela Segovia con las propuestas contemporáneas que estudia Molina Gil en torno al concepto de "logofagia". Según el citado crítico, "el relato social (siempre lingüístico-sígnico) se ve puesto en jaque porque es enfrentado mediante un arma que le es desconocida: la logofagia (...). ¿Cómo combatir lo que no existe o, mejor, lo que desea evaporarse?” (2017: 74). El "no estoy ahi”, el "me fui será", de Ángela Segovia puede entenderse como una forma de resistencia en que el lenguaje prefiere borrarse antes de ser sometido a una verdad prefijada, aunque fuera una verdad propia.

Por otro lado, para ejemplificar el trabajo con la subjetividad de un personaje, escogemos la serie "Fábula de Jai Cuchita y Elmercado, valle de carcas" (¿Valle de Caracas?, ¿referencia al quechuísmo "carca" y/o a su significado coloquial en España?). Las problemáticas que encontramos son similares: el machismo y los efectos de la globalización, sobre todo. Sin embargo, el tratamiento difiere, puesto que el sujeto poético ya no las experimenta en primera persona, sino que acompaña a "Cuchita" en un día de dificultades por "Elmercado". No se trata, por supuesto, de una descripción costumbrista, sino más bien de un expresionismo subjetivo que subraya algunas aristas de la contemporaneidad.

A continuación, espigaremos algunos de los versos de la serie para dar cuenta de la multiplicidad desasosegante a la que se enfrenta el lector: "esta es la salita dedicada a su mujer, aquí, pilar juncosa, exacto / evasión aguerrida, caras en fuga, + tetas y pene, valentía o más bien volantía", "linda la mancha, vea su contorno, vea el punto de choque / la bola roja, enrielada, no, enrelievada, diría", "digo, la globalización, digo, la transparencia normal y global / mejor dicho, así no tenemos problemas, cosas raras, cosas pobres” (2016: 52 - 53). 
Evidentemente, no hay moraleja para esta "fábula", pero sí una sensación de que Cuchita, de que nosotros, hemos caminado por la miseria del mundo para encontrar la fragilidad de sus discursos (bien mirado, también el lenguaje del poder se revela frágil) y situarnos en las fisuras desde las que "ver eso que no puedo ver" (2016: 61).

Por su parte, la serie "europxs. donde más violencia", especialmente en "típicos ríos europeos, cuencas y lo que llevan dentro", se distancia del procedimiento anterior, como si la desorientación esta vez hubiera ganado la partida a los protagonistas (ahora siempre en plural). ¿Quiénes son estas personas que viajan por la periferia de Europa en trenes, en barcos, en "latigazos bruscos"? Podrían ser judíos enviados a campos de concentración, o refugiados sirios huyendo de la guerra: en ambos casos, como en tantos otros, los mecanismos de exclusión, y el dolor que producen, son similares. La ambigüedad superficial del poema se refuerza por el hecho de que Segovia evite el alivio de la catarsis: el lector no puede aferrarse a una resolución sentimental, y esto le obliga a seguir vagando en una "fragilidad salvaje" (2016: $37)$.

Cierro este pequeño recorrido por La curva con el poema "La nubecita negra de los ojos”, la pieza más descoyuntada del libro, puesto que se compone, en su práctica totalidad, de palabras y sintagmas sueltos. Es también uno de los pocos poemas que no se construyen en torno a algún tipo de subjetividad. Esta doble ausencia (de sintaxis y de sujeto) se puede pensar como una indagación en torno a los proceso de despersonalización. Una palabra se repite con insistencia a lo ancho de la página: "requerimiento". En el contexto hispanoamericano, esta palabra trae a la memoria el proceso de conquista, cuando los españoles establecieron un procedimiento legal (el requerimiento) por el cual se exigía sometimiento a los indígenas. Sin importar la incomprensión de los nativos (a los que en muchos casos ni siquiera se les traducía el escrito), a partir de ese momento cualquier acto de resistencia era considerado como una rebelión ilegal.

Como en el caso anterior, el poema de Segovia tiene la virtud de permitir varias lecturas. Quisiéramos aventurarnos a proponer cuatro interpretaciones muy diferentes, al menos en apariencia. Primero, la presencia constante de la "policía", del "registro", de las "razones de seguridad", nos recuerdan los controles a los migrantes. Segundo, el "alumnito" que "trepaba por el muro", en contraste con la "necesidad de formal" nos remite al colegio como proceso de disciplina corporal. Tercero, la necesidad de "ser bonito", asociada al "sin pelo a partes / en partes representativas" se vincula con la imposición de un canon de belleza. Cuarto, el contraste en un mismo verso entre el "requerimiento" y el "+éxito y felicidad", separados por una barra oblicua, explicita la obligación (y la imposibilidad, por su propio carácter obligatorio) de ser exitosos y felices. Por cierto, habrá notado el lector que varias palabras tienen algunas letras en negrita, con lo que la autora quiere señalar vías de escape al sentido habitual de las palabras.

El hecho de que las cuatro interpretaciones, junto a otras que se nos escapan, se sostengan en un mismo poema de escasa extensión importa más allá del virtuosismo técnico. Con este mecanismo, el texto señala la escalofriante semejanza entre los controles policiales, los colegios, los ideales de belleza y los caminos hacia el éxito. Como en el poema con el que comenzábamos este análisis (la "europa multilingüe" babeando en una discoteca), la 
multiplicidad aparente de los discursos del poder remiten a un mismo requerimiento para someternos a los dictados del sistema. En este contexto, la apuesta por la "curva", por el desvío, por la complejidad del lenguaje, se vuelve "barricada", es decir, un acto de resistencia política.

\section{CONCLUSIÓN}

Los tres libros que acabamos de comentar, junto a otros publicados en los últimos años (pensemos en el trabajo de Juan Andrés García Román, Pablo López Carballo, Unai Velasco, Berta García Faet, etc.), suponen una importante apertura en el panorama poético español (si es que todavía podemos separar la poesía escrita en español según los países de nacimiento de sus autores). Más allá de la diversidad de juicios estéticos, estaremos de acuerdo en que estas propuestas marcan una distancia con la poesía española más visibilizada en las últimas décadas (en el polo opuesto, podríamos hablar de continuismo en la obra de autores como Ben Clark o Fernando Valverde, por citar nombres de extenso reconocimiento). No se trata, ni lo pretenden estos autores, de una ruptura adánica, sino más bien de una reconexión con una línea de trabajo en la materialidad del lenguaje que ha sido más frecuente en Latinoamérica (más en Argentina que en Colombia, por ejemplo: no todo el continente es homogéneo en sus búsquedas).

Por otro lado, las propuestas analizadas, en su conjunto, se caracterizan por una búsqueda de la apertura en el lenguaje. Es cierto que todo poema (al menos, todo buen poema) está abierto a una diversidad de interpretaciones, pero aquí la pluralidad se multiplica por la imposibilidad de ejercer una lectura secuencial en torno a un imaginario (es decir, un conjunto de imágenes) coherente. La ruptura con la sintaxis tradicional, en estos casos, se asocia a una huida del discurso homogéneo del poder, ya que este discurso nos encierra en los límites empobrecedores de una explicación única para nuestro estar en el mundo.

A lo largo del artículo, se ha señalado también el mayor peligro de esta apuesta, que es situarse en el terreno de una verdadera insignificancia a través de un lenguaje ensimismado (como sucedía con algunos experimentos en las cortes del Barroco). Al fin de cuentas, la mayoría de estas propuestas (es evidente en ready y en La curva se volvió barricada) parte de la negatividad: cualquier algoritmo puede generar una ruptura del discurso ordenado. El acierto de los tres libros, sin embargo, es que su ruptura no es aleatoria, sino que realmente significan, aunque sea de forma precaria, nuevos espacios para la comprensión de lo público (y de su incidencia en el ámbito privado). En este sentido, estos tres libros son obras muy logradas, a pesar de (o gracias a) la juventud de sus autoras, de quienes deseamos que continúen recorriendo los inciertos caminos del lenguaje fragilizado. 


\section{BIBLIOGRAFÍA}

BAIGORRIA, Martín. "El lenguaje es la mercancía más barata”. Rapallo 1 (2017): 62 - 65

Bueno verA, Carlos. "Un lenguaje que salga y haga su cosa: notas para un arte de la barricada". Nayagua 26 (2017): 195-199.

Dalton, Roque (1969). Taberna y otros lugares. La Habana: Casa de las Américas.

DE LA TORRE, Óscar (2016). Limados. La ruptura textual en la última poesía española. Madrid: Amargord.

FERnÁNDeZ MAllo, Agustín (2009). Postpoesía. Hacia un nuevo paradigma. Barcelona: Anagrama.

GOLDSMITH, Kenneth (2015). Escritura no-creativa. Gestionando el lenguaje en la era digital. Buenos Aires: Caja Negra.

GUERRERO, Gustavo. "Materialismo, realismo y prosaísmo en la joven poesía latinoamericana de los años noventa". Cuadernos de Literatura 20.40 (2016): 382-398.

MARTíNEZ FERnÁNDEZ, Ángela. "La escritura del shock. Crisis y poesía en España"Kamchatka. Revista de análisis cultural 4 (2014): 383-434.

MÉNDEZ RUBIO, Antonio. "Memoria de la desaparición: notas sobre poesía y poder". Anales de Literatura Española, 17 (2004): 121-143.

MOLINA GIL, Raúl. "Sobre la convivencia del silencio y la palabra: para una revisión de la logofagia en la poesía española de las últimas décadas". Dirāsāt Hispānicas. Revista Tunecina de Estudios Hispánicos 4 (2017): 59-77.

MORA, Vicente Luis (2006). Singularidades: ética y poética de la literatura española actual. Madrid: Bartleby.

PUjALS GESALÍ, Esteban. “El 15M: el pie de la letra”. Nayagua 26 (2017): 192-194.

SALGADO, María (2012). ready. Madrid: Arrebato Libros.

SAlgado, María (2016). Hacia un ruido. Frases para un film político. Madrid: Ediciones Contrabando.

SANTAMARÍA, Alberto "La imagen en el poema. Una proyección cartográfi ca de la poesía española reciente." Versants. Revista suiza de literaturas románicas 64.3 (2017): 67 - 79.

SEGOVIA, Ángela (2016). La curva se volvió barricada. Segovia: Ediciones La Uña Rota.

TABARovsky, Damián (2004). Literatura de izquierda. Buenos Aires: Viterbo.

TROTTER, José Ramón. “Devenir ready”. Nayagua 18 (2013): 228 - 230. 